\title{
Suppression of Grain Boundary $\alpha$ Formation by Addition of Silicon in a Near- $\beta$ Titanium Alloy
}

\author{
Masaaki Nakai ${ }^{1, *}$, Mitsuo Niinomi ${ }^{2,3,4}$, Huihong Liu $^{5}$ and Tomonori Kitashima ${ }^{6}$ \\ ${ }^{1}$ Department of Mechanical Engineering, Faculty of Science and Engineering, Kindai University, Higashiosaka 577-8502, Japan \\ ${ }^{2}$ Department of Materials Science and Engineering, Faculty of Science and Technology, Meijo University, Nagoya 468-8502, Japan \\ ${ }^{3}$ Institute for Materials Research, Tohoku University, Sendai 980-5377, Japan \\ ${ }^{4}$ Department of Materials and Manufacturing Science, Graduate School of Engineering, Osaka University, Suita 565-0871, Japan \\ ${ }^{5}$ Joining and Welding Research Institute, Osaka University, Ibaraki 567-0047, Japan \\ ${ }^{6}$ Research Center for Structural Materials, National Institute for Materials Science, Tsukuba 305-0047, Japan
}

The effect of Si addition on the microstructure and mechanical properties of a near- $\beta$ titanium alloy Ti-17 with fully lamella microstructure was investigated. It was found that the microstructure of Ti-17 with silicon exhibited the absence of a continuously thick $\alpha$ layer along prior- $\beta$ grain boundaries (grain boundary $\alpha$ ), while the grain boundary $\alpha$ was distinctively formed in Ti-17 without $\mathrm{Si}$. The formation of (Ti, Zr) silicide particles at the prior- $\beta$ grain interior and its grain boundaries were observed, and the presence of these particles were related to the disappearance of grain boundary $\alpha$ similar to the oxygen scavenging effect of boride particles reported previously. With regard to mechanical properties, Ti-17 with silicon exhibits higher strength and lower ductility compared with Ti-17 without Si. Ductile transgranular fracture morphology was observed even on the fracture surface of Ti-17 with Si after tensile test. [doi:10.2320/matertrans.ME201920]

(Received February 19, 2019; Accepted March 29, 2019; Published May 13, 2019)

Keywords: near- $\beta$ titanium alloy, lamella microstructure, grain boundary $\alpha$, silicide, tensile properties

\section{Introduction}

Ti-5Al-2Sn-2Zr-4Mo-4Cr alloy (Ti-17) is a $\beta$-rich twophase $(\alpha+\beta)$ titanium alloy (near- $\beta$ titanium alloy) used for fan and compressor discs in jet engines. ${ }^{1)}$ These components are spun with blades to meet both high strength and high fracture toughness requirements. In this case, a thermomechanical processing route to form fully lamella microstructure, which is advantageous for obtaining high fracture toughness, ${ }^{2,3)}$ is often utilized for Ti-17 material fabrication. ${ }^{4}$ In the case of fully lamella microstructure, it is generally known that the most influential microstructural parameter of mechanical properties is the $\alpha$ colony size because it determines the effective slip length; yield stress and ductility are likely to decrease, while crack propagation rate decreases with increasing $\alpha$ colony size. ${ }^{5)}$ Further, the continuously thick $\alpha$ layer at prior- $\beta$ grain boundaries (grain boundary $\alpha$ ) cannot be ignored because it has a negative effect on the mechanical properties of Ti-17 with fully lamella microstructure. The grain boundary $\alpha$ enhances the deterioration of ductility ${ }^{6}$ and fatigue properties ${ }^{7)}$ for Ti-17.

Grain boundary $\alpha$ is difficult to eliminate completely; hence, fabricators make an effort to form discontinuous and zigzag-shaped grain boundary $\alpha$ by thermomechanical processing. ${ }^{6}$ A unique method using oxygen scavenging by boride particles has also been proposed for inhibiting the formation of grain boundary $\alpha$ in titanium alloys. ${ }^{8,9)}$ The solid solubility of boron (B) is limited to a low concentration at any temperature, and thus almost all $\mathrm{B}$ included in titanium alloys is precipitated as boride particles. These boride particles are formed during solidification by a eutectic reaction with $\mathrm{Ti}$. Then, they scavenge the oxygen solute, which is an inevitable impurity and is classified as a strong

*Corresponding author, E-mail: nakai@mech.kindai.ac.jp $\alpha$ stabilizer in titanium alloys. In a usual case, the grain boundary $\alpha$ can form at the beginning of $\beta$ to $\alpha$ phase transformation along prior- $\beta$ grain boundaries. ${ }^{10)}$ However, if boride particles are present before phase transformation, the oxygen distribution is inhomogeneous and it has high concentration near the boride particles. In particular, the boride particles can scavenge the oxygen solute from prior- $\beta$ grain boundaries more strongly than from $\beta$ grain interior because atomic diffusion tends to be faster at the grain boundary than in the matrix. As a result, local $\alpha$ stability increases near boride particles and decreases at prior- $\beta$ grain boundaries; this enhances $\alpha$ phase precipitation near boride particles instead of the grain boundary $\alpha$ formation.

Silicon ( $\mathrm{Si}$ ) could play a role similar to $\mathrm{B}$ in inhibiting grain boundary $\alpha$ formation in titanium alloys because of its low solid solubility limit, and silicide forms during solidification by a eutectic reaction with Ti. However, because $\mathrm{Si}$ addition is effective in improving creep resistance at elevated temperature, previous studies have focused on the effects of $\mathrm{Si}$ addition on the microstructure and mechanical properties of $\alpha$ and near- $\alpha$ titanium alloys. ${ }^{1)}$ Therefore, the effects of $\mathrm{Si}$ addition on microstructure and mechanical properties, especially grain boundary $\alpha$ formation, and its effect on tensile properties were investigated for one of the practical near- $\beta$ titanium alloys, Ti-17, in this study.

\section{Experimental}

\subsection{Samples preparation}

Ingots of Ti-17 including 0, 0.3, and 0.6 mass $\%$ Si (Ti-17$0 \mathrm{Si}$, Ti-17-0.3Si, and $\mathrm{Ti}-17-0.6 \mathrm{Si}$, respectively) were prepared by cold crucible levitation melting using an asreceived Ti-17 hot-forged disc and pure silicon grains, which were added at the appropriate proportion in high-purity argon atmosphere. The obtained ingots were homogenized at $1473 \mathrm{~K}$ for $21.6 \mathrm{ks}$ in an argon atmosphere, and subsequently 


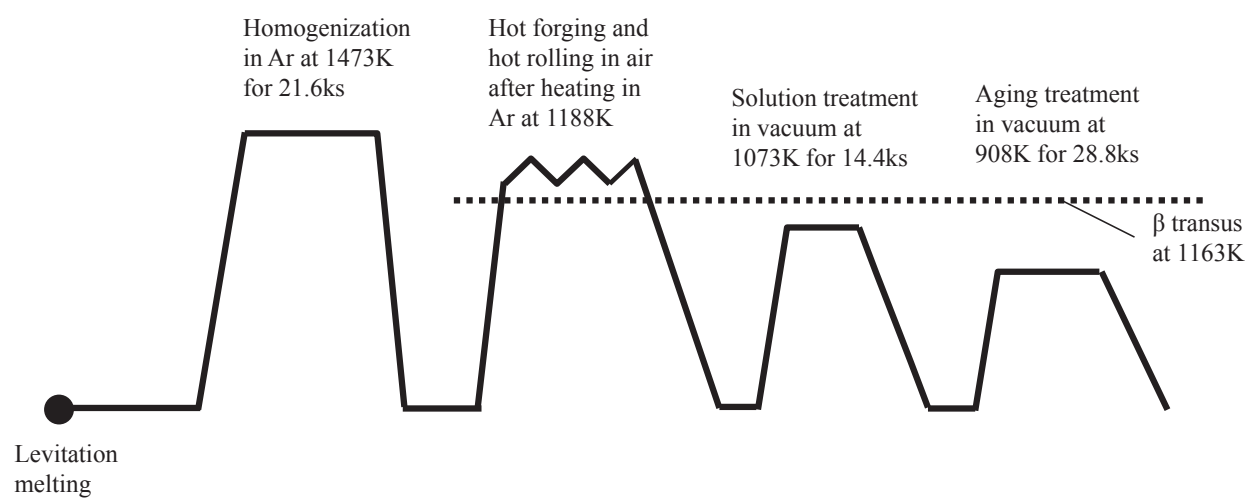

Fig. 1 Preparation procedure of samples of Ti-17 alloys including Si in this study.

quenched in ice water as shown in Fig. 1. However, Ti-17$0.6 \mathrm{Si}$ was broken during this quenching, while the other ingots did not crack. Therefore, only Ti-17-0Si and Ti-17$0.3 \mathrm{Si}$ were available for the following experiments. It has been reported that appropriate amounts of $\mathrm{Si}$ addition to titanium alloys increases the tensile strength while maintaining moderate ductility. ${ }^{11)}$ However, excess $\mathrm{Si}$ addition decreases the ductility of titanium alloys drastically when the silicide particles form a network along the prior $\beta$ grain boundaries, inducing intergranular embrittlement. ${ }^{12,13)}$ Therefore, some researchers optimized the $\mathrm{Si}$ content in each titanium alloy, but the reported optimum contents are not unified in the range of less than 1 mass $\%,{ }^{12-14)}$ indicating that it probably depends on the type of alloys. The Ti-17-0Si and Ti-17-0.3Si ingots were heated in argon atmosphere at $1188 \mathrm{~K}$ and then hot forged into cuboid and hot rolled into plates with approximately $80 \%$ reduction in thickness in air. It is reported that the $\beta /(\alpha+\beta)$ transformation temperature ( $\beta$-transus) of Ti-17 is $1163 \mathrm{~K}^{15}$ ). Therefore, the samples were cooled through the $\beta$-transus of this alloy during hot forging and rolling. The hot-rolled plates were solution-treated at $1073 \mathrm{~K}$ for $14.4 \mathrm{ks}$, and then aged at $908 \mathrm{~K}$ for $28.8 \mathrm{ks}$ followed by air cooling.

\subsection{Microstructural analyses}

The microstructures of Ti-17-0Si and Ti-17-0.3Si were observed using an optical microscopy. The constituent phases and alloying elemental distributions were analyzed by X-ray diffraction (XRD) and field-emission electron probe microanalysis (FE-EPMA), respectively. The specimens for the observation and analysis were polished mechanically using $\mathrm{SiC}$ waterproof emery papers with grit numbers of up to 2400 , and subsequently buff-polished by a colloidal $\mathrm{SiO}_{2}$ suspension in order to obtain a mirror surface. After polishing, the specimens were etched using $\mathrm{HF}+\mathrm{HNO}_{3}$ aqueous solution.

\subsection{Mechanical tests}

Vickers hardness tests were carried out under constant load of $4.9 \mathrm{~N}$ and holding time of $15 \mathrm{~s}$. Tensile tests were performed on each alloy at room temperature using an Instron-type machine at a cross-head speed of $8.33 \times$ $10^{6} \mathrm{~m} \mathrm{~s}^{-1}$. The specimens for the tensile tests were $1.5 \mathrm{~mm}$ thick, $3 \mathrm{~mm}$ wide, and $13 \mathrm{~mm}$ long in the section, and were cut using a wire electric-discharge machine. The tensile specimens were polished using $\mathrm{SiC}$ waterproof emery papers with grit numbers of up to 2400 before the tests. After the tensile tests, the fracture surfaces were observed and analyzed by a scanning electron microscope equipped with an energydispersive X-ray analyzer (SEM/EDX).

\section{Result and Discussion}

\subsection{Microstructures of Ti-17 including $\mathrm{Si}$}

Figure 2 shows the microstructures of Ti-17-0Si and Ti$17-0.3 \mathrm{Si}$ observed by optical microscopy. Both alloys exhibit fully lamella microstructure. The prior- $\beta$ grain sizes of these alloys were not significantly different, while the size homogeneity for Ti-17-0Si was relatively lower than that for Ti-17-0.3Si, as shown in low-magnified micrographs. Further, the grain shapes were not elongated for both alloys. These results indicate that dynamic recrystallization of $\beta$ grains occurred during hot forging and hot rolling; thus, assolidified microstructures disappeared but silicide slightly affected nucleation during this recrystallization. According to the high-magnified micrographs, the greatest difference between the microstructures of these alloys is the prior- $\beta$ grain boundary condition. A continuously thick $\alpha$ layer along the prior- $\beta$ grain boundaries, that is grain boundary $\alpha$, was formed in Ti-17-0Si, while the $\alpha$ layer was not observed in Ti-17-0.3Si. Further, $\alpha$ colony was not clearly observed; hence, the effective slip length is probably dominated by the prior- $\beta$ grains for both alloys. It is also difficult to distinguish the presence of silicide in Ti-17-0.3Si by this observation.

Figure 3 shows the XRD profiles of Ti-17-0Si and Ti-17$0.3 \mathrm{Si}$. Both $\alpha$ and $\beta$ phases were detected, and no significant difference between these alloys was observed. Silicide was not detected in Ti-17-0.3Si by XRD.

Figure 4 shows the alloying element distributions in Ti17-0Si and Ti-17-0.3Si analyzed by FE-EPMA. The $\alpha$ stabilizing elements such as $\mathrm{Al}$ and Ti were enriched, while the $\beta$ stabilizing elements such as Mo and $\mathrm{Cr}$ were depleted in intragranular $\alpha$ lamellae and grain boundary $\alpha$. Sn is a neutral element; hence, its distribution was homogenized in both alloys. On the other hand, $\mathrm{Zr}$ and Si distributions in Ti$17-0.3 \mathrm{Si}$ are distinctive; $\mathrm{Zr}$ was distributed at locations where $\mathrm{Si}$ exists inside prior- $\beta$ grains and at prior- $\beta$ grain boundaries in $\mathrm{Ti}-17-0.3 \mathrm{Si}$, while $\mathrm{Zr}$ was not enriched anywhere in Ti-17-0Si. This result indicates that small $(\mathrm{Ti}, \mathrm{Zr})$ silicide 


\section{(Low magnification)}

(a)

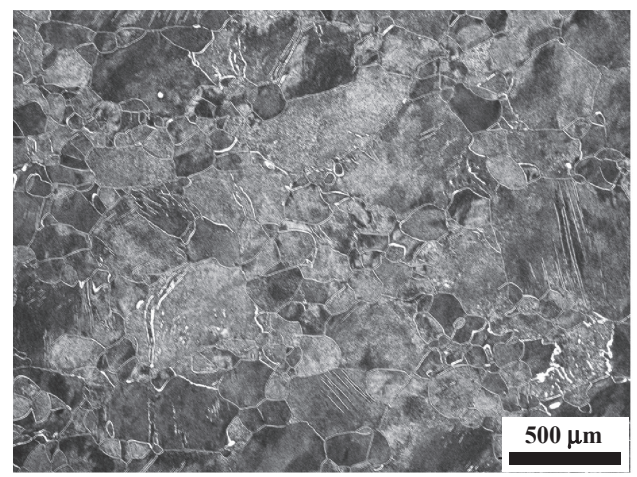

(High magnification)

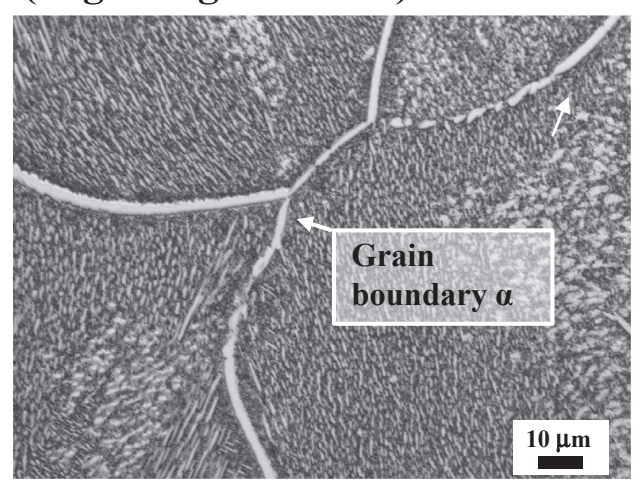

(b)
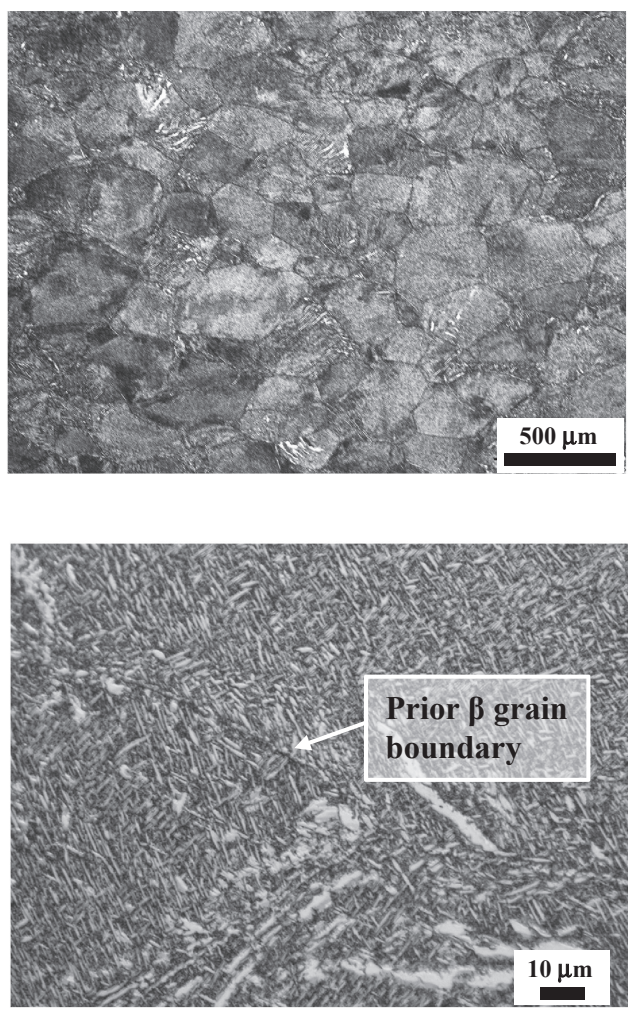

Fig. 2 Optical micrographs of (a) Ti-17-0Si and (b) Ti-17-0.3Si.

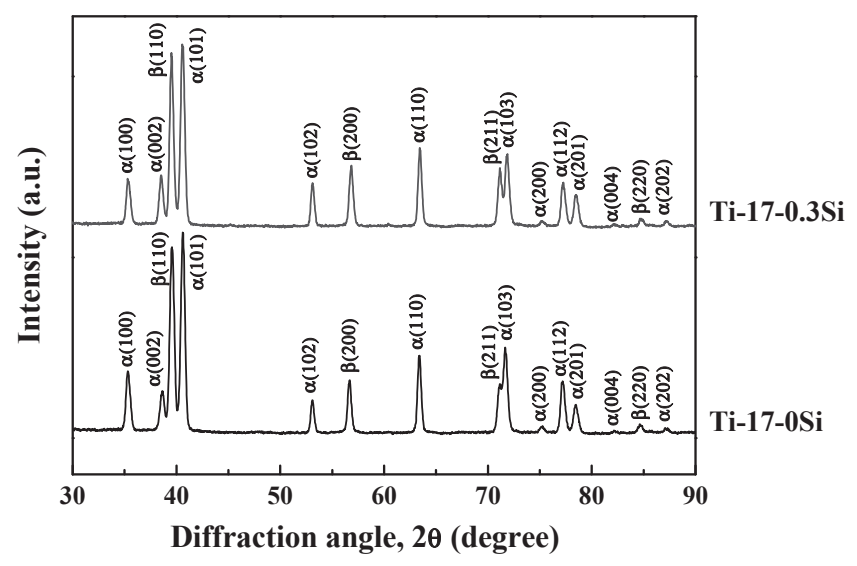

Fig. 3 XRD profiles of Ti-17-0Si and Ti-17-0.3Si.

particles were probably formed inside prior- $\beta$ grains and at prior- $\beta$ grain boundaries. Further, $\mathrm{Zr}$ and $\mathrm{Si}$ concentrations were continuously high along prior- $\beta$ grain boundaries. However, the (Ti, Zr) silicide particles were not continuous at prior- $\beta$ grain boundaries. According to the XRD results (Fig. 3), only $\alpha$ and $\beta$ phases of titanium alloys were identified; no other phase was detected. Therefore, the amount of (Ti, Zr) silicide is not large, and the type of $(\mathrm{Ti}, \mathrm{Zr})$ silicide was not identified in this study. In previous reports, two types of silicides were identified in near- $\alpha$ titanium alloys: $\mathrm{S} 1$ type $(\mathrm{Ti}, \mathrm{Zr})_{5} \mathrm{Si}_{3}{ }^{11,16)}$ and $\mathrm{S} 2$ type $(\mathrm{Ti}, \mathrm{Zr})_{6} \mathrm{Si}_{3} .{ }^{16,17)}$ These silicides formed depending on the $\mathrm{Zr}$ content of the particles. ${ }^{16)}$

It has been reported that the grain boundary $\alpha$ disappears in cast Ti-6Al-4V with $\mathrm{B}$ addition because boride particles were formed during solidification and play a role in getting oxygen, which leads to high oxygen concentration locally near the boride particles and scavenging oxygen from the prior- $\beta$ grain boundaries. As a result, the primary $\alpha$ phase may start to form near boride particles during cooling from the $\beta$ phase region at high temperature above general $\beta$ transus for Ti-17, because oxygen is a strong $\alpha$ stabilizing element. ${ }^{8,9)}$ In general, scavenging effect can be obtained by the addition of alloying element whose affinity for oxygen is stronger than base element. In the case of titanium alloys, rare earth elements are employed as the alloying element for scavenging oxygen. ${ }^{18)}$ Further, it has been reported recently that the rare earth elements were introduced using unstable rare earth compounds such as hydride, boride, silicide, etc. ${ }^{19)}$ The results of in situ synchrotron radiation experiments revealed that yttrium hydride decomposed to metallic yttrium and then yttrium oxide was formed by scavenging oxygen simultaneously in pure $\mathrm{Ti}$ at $1373 \mathrm{~K}$ and $\mathrm{Ti}-6 \mathrm{Al}-4 \mathrm{~V}$ at $1573 \mathrm{~K}^{20}{ }^{20}$ Further, according to the Gibbs free energies for formation of various metallic oxides, the affinity of $\mathrm{Zr}$ for oxygen is stronger than that of $\mathrm{Ti}^{21}$ ) The result of thermodynamic calculation also indicated that $\mathrm{Zr}$ can form oxide preferentially at lower oxygen partial pressure than $\mathrm{Ti}$ and $\mathrm{Si}$ in $\mathrm{Ti}-5 \mathrm{Zr}-(0-0.1) \mathrm{Si}$ system at $1093 \mathrm{~K}^{22}{ }^{22}$ Therefore, a part of (Ti, Zr) silicides could decompose and then $\mathrm{Zr}$ is possible to play a role as a scavenger in Ti-17-0.3Si in this study. As another possible method to obtain scavenging effect, using metastable or substoichiometric oxygen-stabilized titanium compound such as $\mathrm{Ti}_{2} \mathrm{C}$ was proposed; ${ }^{23,24)}$ The $\mathrm{Ti}-\mathrm{C}$ phase diagram suggests that $\mathrm{TiC}$ is the equilibrium phase while $\mathrm{Ti}_{2} \mathrm{C}$ is not. $\mathrm{The}^{\mathrm{Ti}} \mathrm{i}_{2} \mathrm{C}$ particles in titanium alloys 
(a)

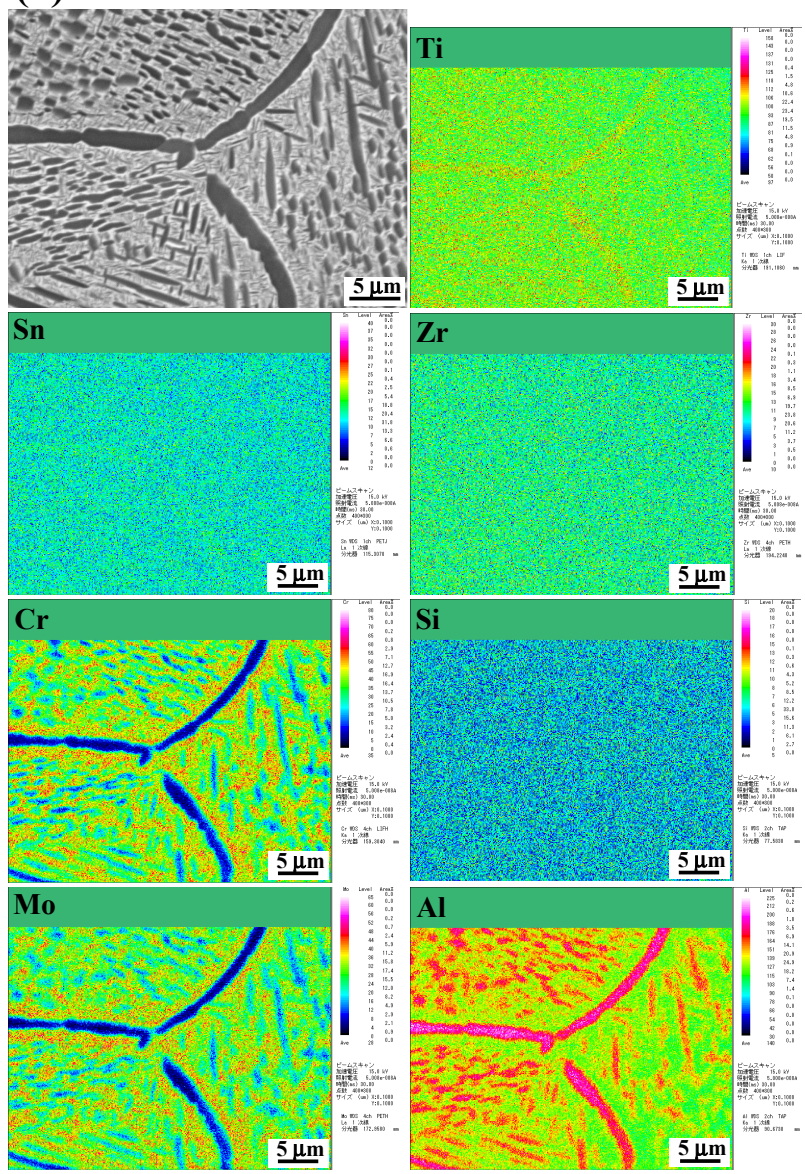

(b)

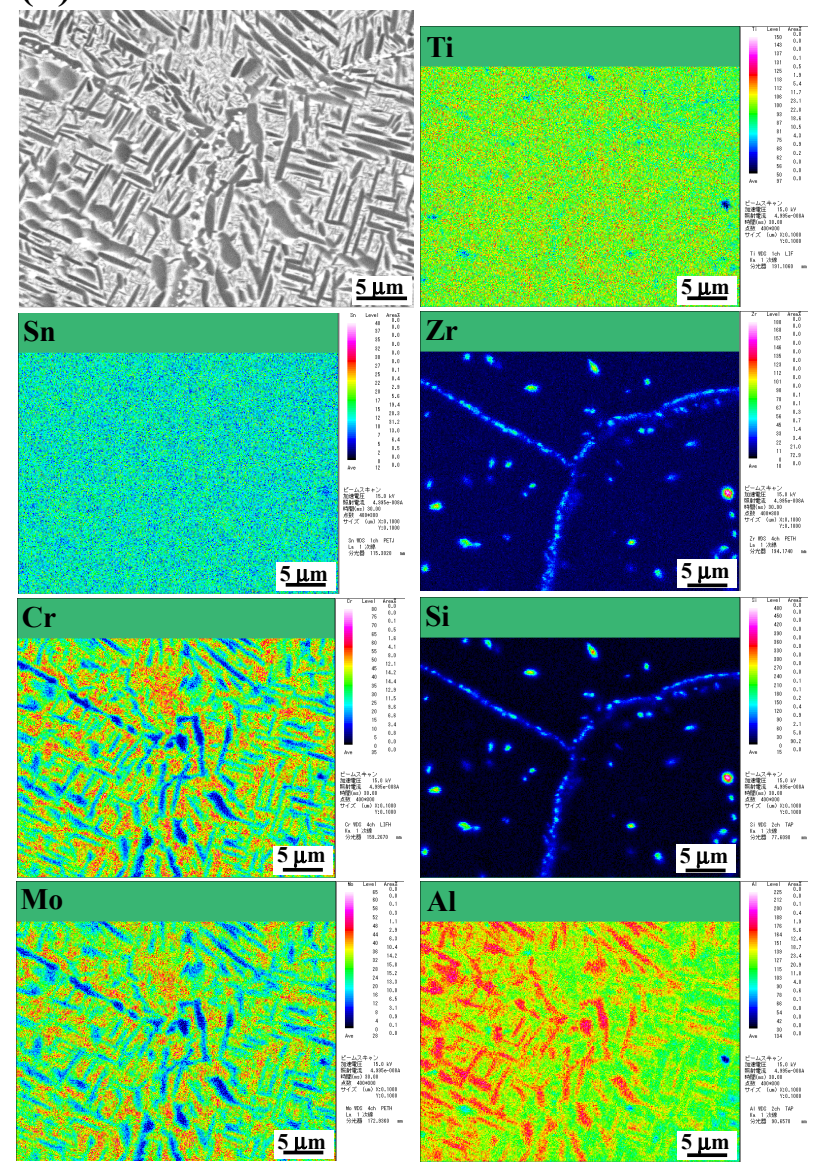

Fig. 4 Alloying element distributions in (a) Ti-17-0Si and (b) Ti-17-0.3Si analyzed by FE-EPMA.

(a)

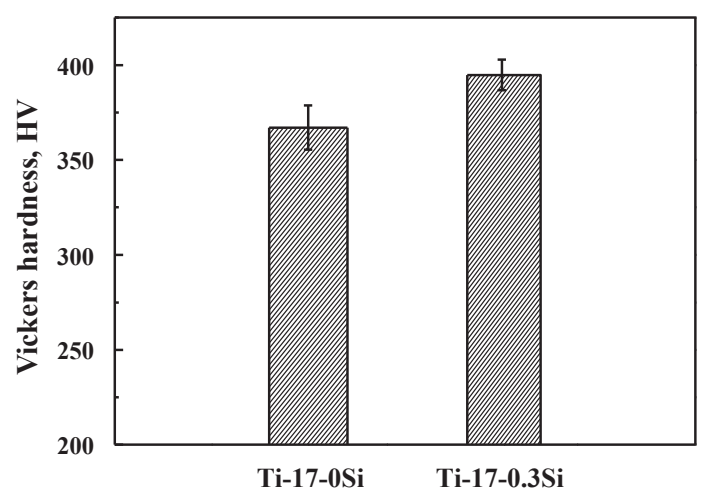

(b)

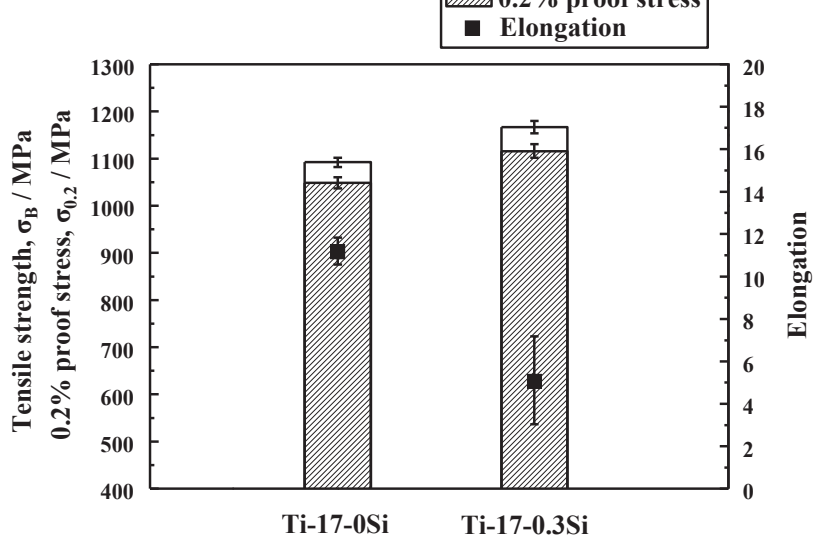

Fig. 5 (a) Vickers hardness and (b) tensile properties of Ti-17-0Si and Ti-17-0.3Si.

could scavenge oxygen via the formation of oxygenstabilized $\mathrm{Ti}_{2} \mathrm{C}$ particles. As the results, local oxygen concentrations at prior- $\beta$ grain boundaries were reduced, resulting in the suppression of grain boundary $\alpha$ formation. The role of titanium boride in scavenging oxygen seems to be similar to that of $\mathrm{Ti}_{2} \mathrm{C}$. In the Ti-Si phase diagram, $\alpha$ and $\beta$ phases are equilibrium with $\mathrm{Ti}_{3} \mathrm{Si}$ below $1444 \mathrm{~K} ;{ }^{25)} \mathrm{Ti}_{5} \mathrm{Si}_{3}$ is a metastable phase so that it is possible to work as a scavenger in Ti-17-0.3Si in this study.

\subsection{Mechanical properties of Ti-17 including $\mathrm{Si}$}

Figure 5 shows the Vickers hardness and tensile properties of Ti-17-0Si and Ti-17-0.3Si. The hardness of Ti-17-0.3Si is slightly higher than that of Ti-17-0Si. The $0.2 \%$ proof stress and tensile strength are higher for Ti-17-0.3Si than for Ti-17-0Si. The elongation of Ti-17-0.3Si is lower than that of Ti-17-0Si.

Figure 6 shows the SEM fractographs of Ti-17-0Si and Ti-17-0.3Si after tensile tests. Ductile transgranular fracture 

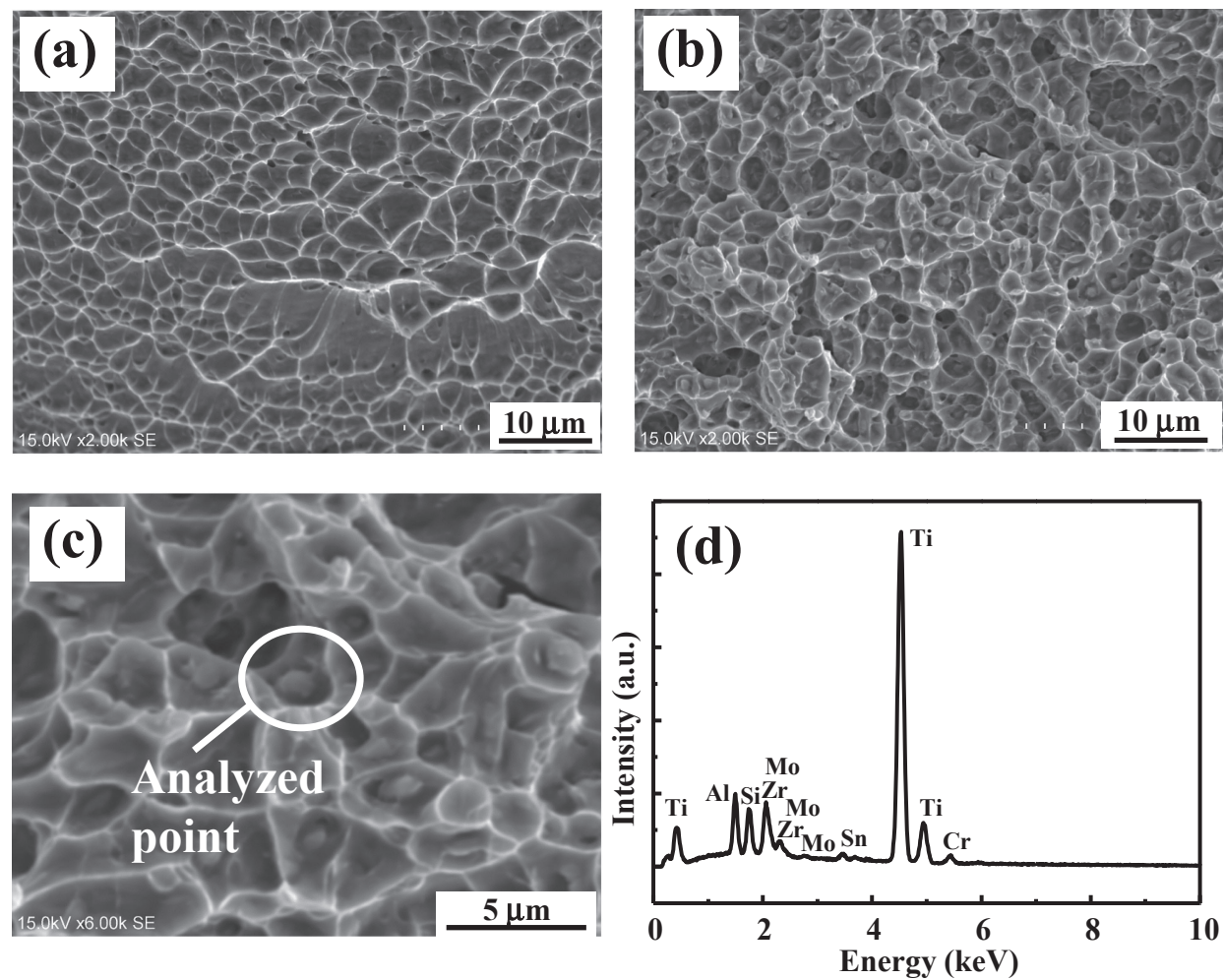

Fig. 6 SEM fractographs of (a) Ti-17-0Si, (b) Ti-17-0.3Si (low magnification), and (c) Ti-17-0.3Si (high magnification) after tensile tests, and (d) result of EDS analysis at an analyzed point shown in (c).

morphologies were observed in the fracture surfaces of both alloys, while some particles were observed inside dimples only in Ti-17-0.3Si. The result of EDX analysis reveals that $\mathrm{Zr}$ and $\mathrm{Si}$ concentrations were high at such the particles in the dimples so that these particles are considered to be the (Ti, Zr) silicide. Therefore, these (Ti, Zr) silicide particles may contribute to strengthening Ti-17-0.3Si. With regard to Ti-17-0Si, transgranular fracture occurred in the tensile tests, although continuously thick grain boundary $\alpha$ was formed. It has been reported that grain boundary $\alpha$ dominates ductility for high-strength $\beta$ titanium alloys with unrecrystallized and elongated $\beta$ grains including $\alpha$ lamellae; tensile ductility decreases drastically when stress is applied at $45^{\circ}$ orientation from the longitudinal axis of the elongated $\beta$ grains. ${ }^{26)}$ It is believed that such ductility anisotropy is caused by both the softer grain boundary $\alpha$ than the matrix and larger effective slip length due to the elongated $\beta$ grain geometry. According to microstructural observations (Fig. 2), the recrystallization of $\beta$ grains probably occurred and then prior- $\beta$ grain shape was not elongated in this study. Therefore, fracture did not occur at grain boundary $\alpha$, specifically in Ti-17-0Si.

\section{Conclusion}

The effect of $\mathrm{Si}$ addition on the microstructure and mechanical properties of the near- $\beta$ titanium alloy Ti-17 with fully lamella microstructure were investigated. The following results were obtained.

(1) The microstructure of Ti-17 with Si showed the absence of continuously thick $\alpha$ layer along prior- $\beta$ grain boundaries (grain boundary $\alpha$ ), while the grain boundary $\alpha$ was distinctively formed in Ti-17 without $\mathrm{Si}$.
(2) (Ti, Zr) silicide particles formed in the prior- $\beta$ grain interior and its grain boundaries. The presence of these particles was related to disappearance of grain boundary $\alpha$, similar to the oxygen scavenging effect of boride particles reported previously.

(3) Ti-17 with $\mathrm{Si}$ exhibits higher strength and lower ductility compared with Ti-17 without Si. Ductile transgranular fracture morphology was observed even in the fracture surface of Ti-17 with Si.

\section{Acknowledgement}

This work was partly supported by the Structural Materials for Innovation, Cross-ministerial Strategic Innovation Promotion Program, Cabinet Office, Government of Japan. The authors thank Mr. S. Iwasaki, Mr. K. Iida, and Mr. T. Hibaru from National Institute for Materials Science (NIMS), Japan for hot forging and rolling and Kobe Steel, Ltd. for providing the material.

\section{REFERENCES}

1) R.R. Boyer: Mater. Sci. Eng. A 213 (1996) 103-114.

2) T. Matsumoto and T. Nishimura: Tetsu-to-Hagané 72 (1986) 138-145.

3) R. Liang, Y. Ji, S. Wang and S. Liu: Metals (Basel) 6 (2016) 186.

4) K. Gangwar and M. Ramulu: Mater. Des. 141 (2018) 230-255.

5) G. Lütjering: Mater. Sci. Eng. A 243 (1998) 32-45.

6) H. Oyama, S. Ishigai and T. Kida: R\&D Kobe Steel Eng. Reports 49 (1999) 23-25.

7) S. Zhang, W. Zeng, X. Gao, X. Zhao and S. Li: J. Mater. Eng. Perform. 26 (2017) 5016-5026.

8) S. Roy, V. Tungala and S. Suwas: Metall. Mater. Trans. A 42 (2011) 2535-2541.

9) S. Roy, S. Suwas, S. Tamirisakandala, R. Srinivasan and D.B. Miracle: 
Mater. Sci. Eng. A 540 (2012) 152-163.

10) N. Stanford and P.S. Bate: Acta Mater. 52 (2004) 5215-5224.

11) M. Jayaprakash, D.H. Ping and Y. Yamabe-Mitarai: Mater. Sci. Eng. A 612 (2014) 456-461.

12) Y.F. Yang, S.D. Luo, G.B. Schaffer and M. Qian: Metall. Mater. Trans A 43 (2012) 4896-4906.

13) A.M.G. Tavares, W.S. Ramos, J.C.G. de Blas, E.S.N. Lopes, R. Caram, W.W. Batista and S.A. Souza: J. Mech. Behav. Biomed. Mater. 51 (2015) 74-87.

14) A. Suzuki, T. Noda and M. Okabe: Denki Seiko (Electr. Furn. Steel) 73 (2002) 101-106

15) R. Boyer, G. Welsch and E.W. Collings: Materials Properties Handbook: Titanium Alloys, (ASM International, Materials Park, $\mathrm{OH}$ USA, 1994).

16) A. Popov, N. Rossina and M. Popova: Mater. Sci. Eng. A 564 (2013) 284-287.

17) C. Ramachandra, A.K. Singh and G.M.K. Sarma: Metall. Trans. A 24 (1993) 1273-1280

18) Y. Liu, L. Chen, W. Wei, H. Tang and B. Liu: J. Mater. Sci. Technol. 22
(2006) 465-469.

19) Y.F. Yang, S.D. Luo, G.B. Schaffer and M. Qian: Mater. Sci. Eng. A 573 (2013) 166-174

20) M. Yan, Y. Liu, G.B. Schaffer and M. Qian: Scr. Mater. 68 (2013) 6366.

21) M. Yan, H.P. Tang and M. Qian: Scavenging of Oxygen and Chlorine from Powder Metallurgy (PM) Titanium and Titanium Alloys, (Elsevier Inc., 2015).

22) S.-H. Ha, B.-H. Kim, Y.-O. Yoon, H.-K. Lim and S.K. Kim: Arch Metall. Mater. 63 (2018) 1493-1495.

23) Z.Q. Chen, D. Hu, M.H. Loretto and X. Wu: Mater. Sci. Technol. 20 (2004) 343-349.

24) X.H. Wu, J. del Prado, Q. Li, A. Huang, D. Hu and M.H. Loretto: Acta Mater. 54 (2006) 5433-5448.

25) M. Fiore, F. Beneduce Neto and C.R. de Farias Azevedo: Mater. Res. 19 (2016) 942-953.

26) C. Sauer and G. Luetjering: J. Mater. Process. Technol. 117 (2001) 311-317. 